\title{
Unprecedented public health effort tackles soaring TB rates in Nunavut
}

\author{
— Cite as: CMAJ 2019 September 9;191:E1010-1. doi: 10.1503/cmaj.1095779
}

Posted on cmajnews.com on August 20, 2019

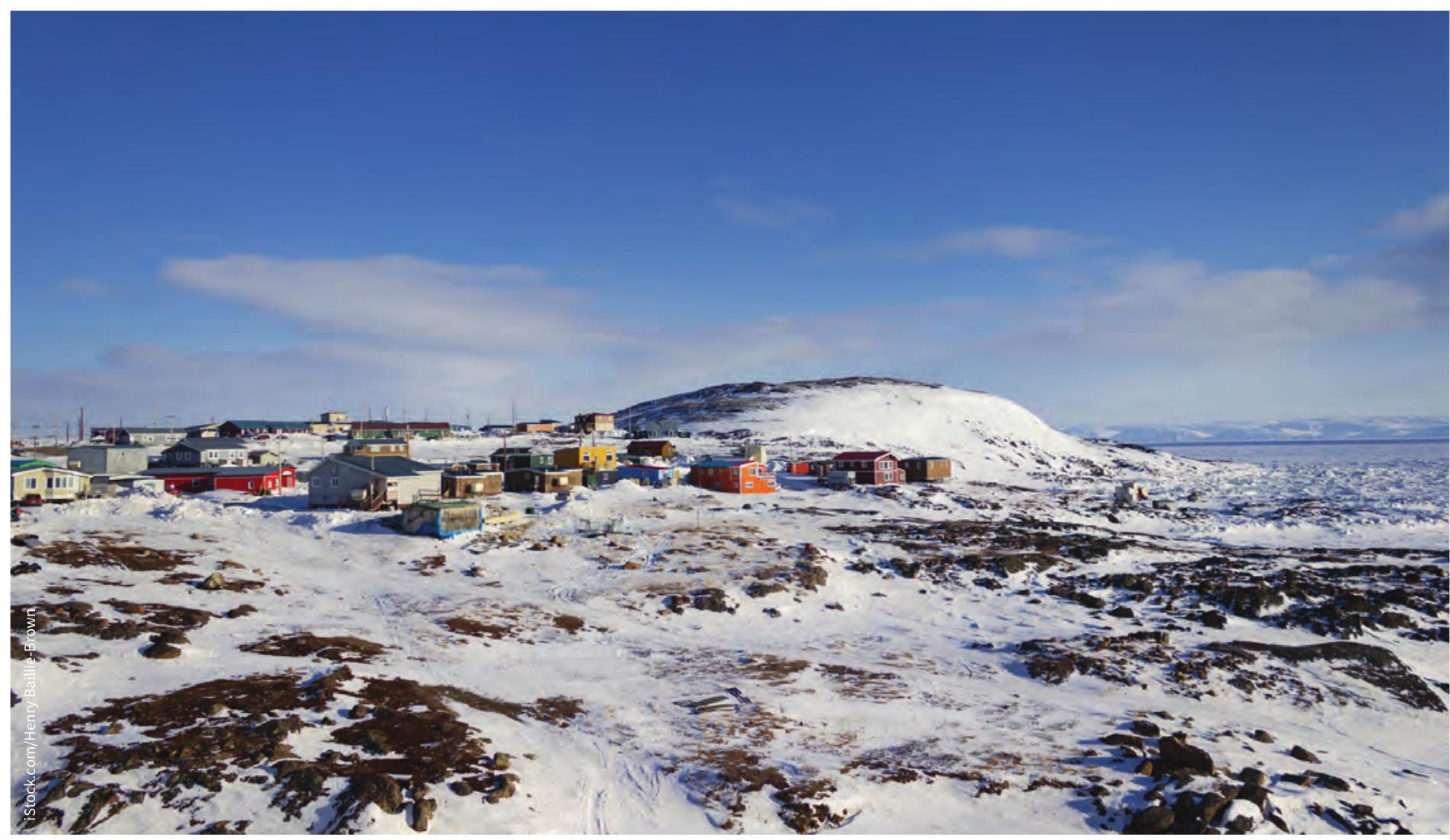

Communities in Nunavut are struggling with high TB rates and some are holding mass-screening clinics to help combat the problem.

E scalating rates of tuberculosis (TB) among Inuit people in Canada's north have led to mass-screening clinics involving federal and territorial governments, communities, and the latest diagnostic technology and treatment.

"Overall, Canada has one of the lowest rates of TB in the world," said Dr. Howard Njoo, deputy chief public health officer at the Public Health Agency of Canada (PHAC). But the rate in the Inuit population stood at 205.8 per 100,000 in 2017 (latest figures). The number of newly diagnosed cases among Inuit people was 142 that year, lower than the peak of 161 in 2012 but still similar to 2017 rates in Cameroon, Uganda, and India.

The causes are the same as in other locations, said Njoo: "overcrowding, poor housing, poverty, poor nutrition, overuse of alcohol and tobacco."

The epidemic has hit Nunavut hard, said Dr. Michael Patterson, chief medical officer of health for the territory. "In our two worst years, 2010 and 2017, we had 100 active cases of TB in a population of roughly 38000 people."

In January 2017, a young Inuk woman died of TB in Qikiqtarjuaq, a remote Nun- avut community. Increasing numbers of community residents were diagnosed with active TB throughout that year. "The consensus among the health department and experts was that there was potential for everybody in the community to be exposed to TB," said Dr. Patterson. "The standard contact tracing to track people down was probably not appropriate. The decision was made to do a mass-screening clinic, and, as much as possible, to get everyone tested."

The first clinic, held in Qikiqtarjuaq for six weeks beginning in February 2018, resulted in $96 \%$ of residents presenting at 
least once and about $85 \%$ completing screening, said Patterson. Clinics were subsequently held in other communities.

Such intensive screening required cooperation at all levels of government. "There's a lot more to it than just the government of Nunavut," said Patterson. At the federal level, Indigenous Services Canada provided leadership and funding; PHAC provided technical support, supplies and personnel. Communities were also involved, to counteract the legacy of forced removal of Inuit for TB treatment in the 1950s.

Local mayors announced the clinics on radio in English and Inuktitut, and public health staff met with town elders and community councils. The communities held feasts at the beginning and end of clinics. If patients needed to travel south for investigation and treatment, they received a thorough explanation and were involved in their own care decisions.
Clinics also marked medical milestones. Samples were tested immediately on site, using a tabletop containment lab, said Catherine Yoshida, head of diagnostic and reference services at PHAC's National Microbiology Laboratory (NML) in Winnipeg, who worked at the clinics. The portable lab "folds up really compact, like you were going camping."

Once set up, all equipment and supplies for the containment lab are put in a plastic tent, which is zipped up. Staff put their hands in gloves through one side to carry out tests. In Nunavut, the lab was used inside a closet to add a physical barrier in case of bacterial release. Test results were available in as little as two hours and showed not only whether the sample was positive, but also whether it was resistant to the common TB drug rifampicin. No drug-resistant samples were found.
The NML staff worked side by side with Nunavut technologists, entering data into lab information systems and communicating about positive cases. They also met local residents at a karaoke night and a fishing derby, which gave them a chance to answer questions informally about TB. "It's all about decreasing fear and stigma associated with the disease," said Yoshida.

Patterson said the clinics led to large workloads for local health centres, even with new TB treatment regimens that require only 12 weeks. "These are things we have to factor into our planning."

Efforts are underway to evaluate how effective the clinics have been. The aspirational goal is to eliminate $T B$, but "if we could halve the rate and show that we're making regular progress, that's the way we'd like to go," said Njoo.

Carolyn Brown, Ottawa, Ontario 